\title{
A Study on Association of Serum Levels of Lipoprotein(A)And Stroke Severity
}

\author{
B.Gowrishankar ${ }^{1, P . S . R a m e s h}{ }^{2,}$ S.P.Kumaresan ${ }^{3}$ R.Aswinth ${ }^{4,}$ Ashwinimetry $^{5}$ \\ S.Aravinda Kumar $^{6}$ \\ ${ }^{1,2}$ Assistant professor, ${ }^{3}$ Associate professor department of medicine, Government vellore medical college. \\ ${ }^{4,5,6}$ Postgraduate, department of medicine, Government vellore medical college.
}

\begin{abstract}
:
Introduction: Stroke or cerebrovascular accident is a major public health problem in India .stroke presents as an emergency clinical situation. The risk factors of stroke are hypertension, diabetes mellitus, dyslipidemia, smoking etc,. the association between lipoprotein (a) and cardiovascular mortality is well established. This study establishes stroke severity in relation to lipoprotein (a).

Objective: To determine the association of serum levels of liporotein(a) association of stroke severity in stroke patients admitted in Government Stanley Medical College, Chennai.

Meterials And Methods: Fifty adult patients presenting with acute ischemic stroke, occurring within 24 hours, confirmed by CT scan admitted in Government Stanley Medical College and hospital, Chennai from June 2012 to December 2012 were included in this study and each patient fasting serum lipoprotein(a) levels were estimated.

Results: The total number of patients included in this study was 50. There were 26 male patients and 24 female patients. The correlation coefficient were 0.069 in the negative range. Slight negative correlation exists among the female subjects between lipoprotein level and stroke severity. The statistical significance exists but not large enough in females, it needs further evaluation. The correlation coefficient in the age group below 60 years was studied. Among the male patients studied there exists no correlation. But in the female patients the Lipoprotein(a) measurement has negative correlation with the correlation coefficient being -0.212 . When the serum Lp(a) level is correlated with the stroke severity, the mean among the patients with moderate score is $120 \pm 82.03$ and the mean with severe score is 107.33 \pm 74 .6. On analysing the above samples the association with $L p(a)$ with male patients the mean values in the moderate score group is 103.7+/-67.8 and 91.05+/- 64.95. The mean elevations once again correlates in the moderate score group among the male patients

Conclusion: In my study great care is taken to exclude the possible confounding factors like diabetes mellitus patient, renal failure patients, liver failure etc but the role of other risk factors like smoking, obesity and also the circulating concentration of fibrinogen along with genetic and environmental could not be definitely excluded. Despite these limitations, the presence of statistical significance of lipoprotein(a) associations with stroke severity in men of below 50 years age group opens a new scope for future research.
\end{abstract}

Keywords: Lipoprotein(a), stroke, LDL, HDL, Hypertension.

\section{Introduction}

Stroke or cerebrovascular accidents (CVA) is a major public health problem in India. ${ }^{1}$ Stroke is the abrupt onset of loss of functions of brain manifested clinically by neurological deficit. It is caused by the disturbances of blood supply either by ischemia or hemorrhage. Infarct of the brain occurs when the ischemia or the reduction of blood supply is prolonged. Cerebral hemorrhage can occur when blood leaks directly into brain tissue or into the ventricles and then to the subarachnoid space. There is permanent neurological damage when the reduction in blood supply persists for more than 24 hours but if the brain functions recover within a day it is termed as transient ischemic attack (TIA). When there is widespread hypoxia or ischemia to the brain it results in impairment of cognition known as hypoxic-ischemic encephalopathy. Stroke presents as an emergency clinical situation. Modern radiological investigations aid in delineating the dead and the salvageable brain tissue, where appropriate management could arrest the ongoing functional loss of neurons. The risk factors of stroke are hypertension, smoking, dyslipidemia, heart disease, diabetes mellitus etc. Physicians have a large role to play in this important public health problem.Stanley Medical College caters to a large population of people in and around North Chennai. We physicians come across a good number or stroke patients. In my study I correlated the levels of lipoprotein(a) with stroke severity.Lipoprotein(a) is a particle very similar to LDL cholesterol. It also contains a component which is like a blood clotting protein, plasminogen, hence lipoprotein(a) may play a role in blood clot formation. The association between lipoprotein(a) levels and cardiovascular mortality is well established. An effort is made in this study to establish whether the stroke 
severity is related to lipoprotein(a) level. The severity of stroke is measured in our patients using NIHS stoke severity scale.

\section{Aim And Objectives}

1.To evaluate the serum lipoprotein a level in stroke patients.

2.To correlate the levels of lipoprotein a with the stroke severity.

3.To find out the prognostic significance of

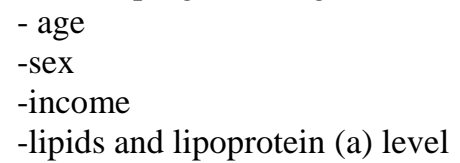

4.To compare the results with the literature

5.To establish the inmportance of risk factors in stroke patients.

\section{Study Design}

\section{Materials And Methods}

Single centre cross sectional study done on adults attending Government Stanley medical college and hospital between June 2012 to December 2012.In this study fifty patients presenting with acute ischemic stroke, occurring within 24 hours, confirmed by CT scan admitted in Government Stanley medical college and hospital, Chennai from June 2012 to December 2012 were included in this study and each patient fasting serum lipoprotein(a) levels were estimated.

\section{Inclusion Criteria}

Patients with first ever ischemic stroke occurring within 24 hours, confirmed by CT scan, admitted to admitted in government Stanley Medical College and Hospital, Chennai from June 2012 to December 2012.

\section{Exclusion Criteria}

Patients admitted to the hospital $>24$ hours after stroke onset,Previous history of stroke,,Haemorrhagic stroke, space occupying lesions, Patients with CVT, Coronary Artery Disease Patients, Renal Failure Patients,ObesePatients, Patients With H/O Bleeding Disorders.

\section{Method of collection of data}

A CT scan head (MRI brain where required) was taken within 24 hours of stroke onset for all with first ever stroke admitted in government Stanley Medical College and Hospital, Chennai from June 2012 to December 2012 .Stroke severity on admission was assessed using National Institute of Health Stroke Scale (NIHSS). The patients were divided into 2 groups: those with severe stroke, score $>15$ and those with moderate stroke, score $<15$. Systemic hypertension was diagnosed when 2 readings of systolic blood pressure were $\geq 140$ $\mathrm{mm} \mathrm{Hg}$ or diastolic blood pressure $\geq 90 \mathrm{~mm} \mathrm{Hg}$.patients history was obtained and the past treatment records were analysed to know whether they are a known case of CAD or DM. the present investigations were also looked into. In addition to routine investigations as per standard protocol in the evaluation of stroke patient, fasting serum lipoprotein(a) level and total cholesterol were measured. The samples were taken on the day of admission to the hospital as early as possible keeping in mind the onset of stroke at home. Patients were followed up till they were discharged from the hospital.

\section{Procedure}

A detailed history, clinical examination and relevant laboratory investigations were done as per proforma. Fasting serum lipoprotein(a) levels were estimated in patients, quantitatively by using LPAX IN Human Serum Or Plasma By Rate Nephelometry.The Kit Used Was Lipoprotrin(a) Lpax Kit:Beckman Coulter, Immage Immunochemistry Systemsireland.

\section{Principle}

The LPAX test measures the rate at which the light scatters because of the suspended particles in the solution. This is largely due to the formation of antigen-antibody reaction. 


\section{Chemical Equation}

First the $\mathrm{Lp}(\mathrm{a})$ present in the human sample reacts with the antibody which is already bound to particles it then forms the antigen antibody complex, which can be measured quantitatively.

\section{Lp(a) sample + anti-lipoprotein(a) (antibody) -> Lipoprotein (a)(sample)-antibody complex}

Test:

Type Of Specimen - a fasting serum sample,which is freshly drawn.General Instructions the blood samples are kept closed and left to stand in a vertical position.after centrifugation the serum is separated within two hours from the time of collection. The centrifugation is done at $360 \mathrm{rpm}$ for two minutes for separation of serum. The samples can be stored at +2 to $+8{ }^{0} \mathrm{C}$.

\section{Chemical Reagents}

Each kit contains the following items: the antibody _lpax cartridge,evaporationcapslpax reagent bar code card,reactive ingredients,lpax antibody (particle bound polyclonal anti-lipoprotein(a) antibody;rabbit.,sodium azide (preservative),sometimes the bovine serum samples are used.

\section{Reference Intervals}

The LPAX its own reference values for human serum lipoprotein(a), using the IMMAGE and the ARRAY 360 immunochemistry systems.

The results are reported in $\mathrm{mg} / \mathrm{dl}$.

The LPAX test is detects concentrations using an 1:36 sample dilution

IV. Results

The following are the parameters which were looked into to study about the results

\section{Statistical Measures}

\begin{tabular}{|l|l|l|}
\hline Parameters & Numbers & Percentage \% \\
\hline Age & 50 & 100 \\
\hline Age $<60$ & 29 & 58 \\
\hline -male & 16 & 32 \\
\hline -female & 13 & 26 \\
\hline Age $>60$ & 21 & 42 \\
\hline -male & 10 & 20 \\
\hline & 11 & 22 \\
\hline -female & 29 & 58 \\
\hline SSS-moderate & 21 & 42 \\
\hline SSS-severe & 7 & 14 \\
\hline LDL-elevated & 43 & 86 \\
\hline LDL-normal & &
\end{tabular}

Association Between Lp(A) \&Stroke Severity

\begin{tabular}{|l|l|l|}
\hline Parameters & Sample Size & Correlation Coeffficient \\
\hline Total & $\mathbf{5 0}$ & $\mathbf{- - 0 . 6 9}$ \\
\hline Male & $\mathbf{2 6}$ & $\mathbf{- 0 . 5 2 3}$ \\
\hline Female & $\mathbf{2 4}$ & $\mathbf{- - 0 . 2 2 6}$ \\
\hline
\end{tabular}

The total number of patients included in this study was 50. There were 26 male patients and 24 were female patients. The correlation coefficient were 0.069 in the negative range. Slight negative correlation exists among the female subjects between lipoprotein level and stroke severity. The statistical significance exists but not large enough in females, it needs further evaluation.

\section{Conclusion}

This study highlights the fact once again that the difficulty in using the lipoprotein(a) in assessing the severity of stroke is of negligible value as the negative correlation in the female is not found in the total patients included in the study.

Correlation analysis according to age Age below 60 years

\begin{tabular}{|l|l|l|}
\hline & Sample size & Correlation coefficient \\
\hline Total & 29 & --0.1626 \\
\hline Male & 16 & $\mathbf{0 . 9 0 3 4}$ \\
\hline Female & 13 & --0.212 \\
\hline
\end{tabular}


The correlation coefficient in the age group below 60 years was studied. Among the male patients studied there exists no correlation. But in the female patients the Lipoprotein(a) measurement has negative correlation with the correlation coefficient being -0.212 .

\section{Conclusion}

There is a negative correlation among the female patients included in the study, but it is not statistically significant.

Correlation Analysis According To Age Age Below 50 Years
\begin{tabular}{|l|l|l|}
\hline Total & Sample Size & Correlation Coeffecient \\
\hline Male & 7 & 0.317 \\
\hline Female & 3 & --- \\
\hline
\end{tabular}

Among the patients below 50 years the number of samples is less totalling about 10.Eventhough the female patients between 50 to 60 years showed statistical significance,it could not be proved in the below 50 years age group. A trace of positive correlation seen among the male patients below 50 years of life.

Conclusion: The positive correlation seen among the younger below 50 years age group is statistically significant. To prove the significant P-value large number of study subjects should be included in the study.

Statistical Analysis For Significance For Lp(A) Level With Stroke Severity
\begin{tabular}{|l|l|l|l|}
\hline & Sample Size & Mean & Standard Deviation \\
\hline Moderate & 29 & 120 & 82.03 \\
\hline Severe & 21 & 107.33 & 74.6 \\
\hline Total & 50 & - & - \\
\hline
\end{tabular}

When the serum $\mathrm{Lp}$ (a) level is correlated with the stroke severity, the mean among the patients with moderate score is $120 \pm 82.03$ and the mean with severe score is $107.33 \pm 74.6$.

Conclusion: -The statistical mean does not clearly suggest a definite elevation in both the moderate group and the severe group which could be considered statistically significant. The slight elevation in the moderate group needs further study.

Association Of Lp(A) With Males

\begin{tabular}{|l|l|l|l|}
\hline Male & 26 & Mean & Standard Deviation \\
\hline Moderate & 18 & 103.7 & 67.8 \\
\hline Severe & 8 & 91.05 & 64.95 \\
\hline
\end{tabular}

On analysing the above samples the association with $\mathrm{Lp}(\mathrm{a})$ with male patients the mean values in the moderate score group is $103.7+/-67.8$ and $91.05+/-64.95$.

Conclusion:-The mean elevations were once again correlates in the moderate score group among the male patients.

Table-14: Association Between $\operatorname{Lp}(\mathrm{A}) \& \mathrm{Ldl}$

\begin{tabular}{|l|l|l|l|}
\hline Sex & Age Group Below 60 & Age Group Above 60 & Total \\
\hline Male & 16 & 10 & 26 \\
\hline Female & 13 & 11 & 24 \\
\hline Total & 29 & 21 & 50 \\
\hline
\end{tabular}

The number of patients below 60 years was 29 and above 60 years was 21.There was almost equal distribution among the age group with negligible increase in the below 60 years age group.

Association Of Lp(A) With Sex-

\begin{tabular}{|l|l|l|l|}
\hline Female Below 60 & 13 & Mean & Standard Deviation \\
\hline Moderate & 3 & 139.5 & 75.78 \\
\hline Severe & 10 & 131.29 & 87.72 \\
\hline
\end{tabular}


Among the male patients aged below 60 years the Lipoprotein (a) level wasincreased among the severe score with mean of $124.75+/-80.94$ than with themoderate score with the mean of $103.6+/-77.9$ using the students ' $\mathrm{T}$ ' test.

: Association Between Lp(A) \&Ldl

\begin{tabular}{|l|l|l|l|}
\hline Sex & Age Group Below 60 & Age Group Above 60 & Total \\
\hline Male & 16 & 10 & 26 \\
\hline Female & 13 & 11 & 24 \\
\hline Total & 29 & 21 & 50 \\
\hline
\end{tabular}

The below 60 years age group of patients in the males the correlation coefficient was 0.724 , with the $p$ value of $<0.01$ there is a high positive correlation.

\begin{tabular}{|l|l|l|l|}
\hline Below 60 Age Group Analysis \\
\hline Sex & Sample Size & Corre Coef & S.D/P Value \\
\hline Male & 16 & 0.7240 & P $<0.01$ \\
\hline Female & 13 & 0.0365 & Nsd \\
\hline
\end{tabular}

Conclusion:- Lipoprotein(a) measurement will be useful to assess the severity of stroke in male patients particularly in the younger age group patients, as the positive correlation exists in the below 60 years age group.

\begin{tabular}{|l|l|l|}
\hline :Association Lp(A) With Hypertension \\
\hline Total & 50 & 24 \\
\hline Male & 26 & 11 \\
\hline Female & 24 & 13 \\
\hline
\end{tabular}

\section{Discussion}

\section{Diagnosing stroke}

There are various systems in practice which helps in early recognition of stroke. They are FAST - Force, Arm, Speech, Time, LAPSS - Los Angeles Pre-hospital Stroke Screen, CPSS - Cincinnatti Pre-hospital Stroke Scale. By using the scales, the extent of damage can be limited by instituting appropriate therepy at the earliest.In this study National Institute of Health Stroke Severity Scale is used because of the comprehensive scoring system where all the parameters like motor ,sensory,cranial nerves and cognition were taken into account. The NIH stroke scale is attached in the end of this discussion.Lipoprotein(a) level measurement serves as good predictor of atherosclerosis in many diseases involving the coronary artery. But with regard to the involvement of the vascular disease of nervous system there is conflicting evidence. Various studies like Peynet et al,ichinose et al, Van kooten et al Margoglione et al are some of the studies to quote which established that lipoprotein(a) is a risk factor for ischemic stroke. The other studies like Glader et al, Hachinski et al, physician health study could not irrevocably prove or the results obtained were against the earlier studies. In my study increased LDL concentration were significantly associated with elevated lipoprotein(a) level.but the overall associations of lipoprotein(a) level could not be consistently proved.

\section{Normal values $^{37}$}

\begin{tabular}{|lc|c|c|}
\hline Desirable & $:$ & $<14 \mathrm{mg} / \mathrm{dl}$ & $(<35 \mathrm{nmol} / \mathrm{L})$ \\
\hline Border line risk & $:$ & $14-30 \mathrm{mg} / \mathrm{dl}$ & $(35-75 \mathrm{nmol} / \mathrm{L})$ \\
\hline High risk & $:$ & $31-50 \mathrm{mg} / \mathrm{dl}$ & $(75-125 \mathrm{nmol} / \mathrm{L})$ \\
\hline Very high risk & $:$ & $>50 \mathrm{mg} / \mathrm{dl}$ & $(>125 \mathrm{nmol} / \mathrm{L})$ \\
\hline
\end{tabular}

$40 \%$ of variation occurs because of different isoforms.In the study done by Hatchinski et al in the year 1996 , it was proved that LDL levels were associated with atherothromboticrisk.but the statistical significance was not there with lipoprotein(a) concentrations. Similarly in the Physician Health study done in 1995, the participating physicians were followed up for a period of 7.5 years. In this study the baseline lipoprotein(a) levels could not be correlated with the future risk of ischemic stroke. The patients included in this study were of varied age group because of the convenient sampling method. By nthis method the patients were included in the study as and when they are brought to the Govt. Stanley hospital after looking into the exclusion criteria. With regard to the correlation analysis in the lipoprotein level and the LDL level there is a high degree of positive correlation with standard deviation $(\mathrm{P}<0.01)$ among the below 60 years age group of male patients. Also there exists a slight negative correlation in the female patients, especially in the below 60 years age group On increasing thee sample size or by the number of patients included below 50 years of age the good positive correlation with statistical significance can be achieved. Further studies could be more enlightening when the number of patients included along with other risk factors of stroke. 


\section{Limitations}

The small sample size in the study group, where the age group and the statistical significance of the males and females could not be individually made out.The presence of Type 11 error can be overcome by increasing the sample size below 50 years age group, especially in the female age group.As the other risk factors were excluded in the study the role of such factors and their influence in the stroke severity and lipoprotein (a) values were yet to be ascertained.

\section{Conclusion}

Thus the available literature and the research journals have put forth contradicting versions of the lipoprotein(a) level associations with the stroke severity. Compounding to this fact is lack of universally accepted method of evaluating the serum level of lipoprotein(a) assessment. The general view is that the samples included in the studies were usually of small size and were done on a selected number of patients with small ethnic backgrounds. The role of female hormones in the influence of $L p(a)$ measurement is yet to be ascertained. In my study great care is taken to exclude the possible confounding factors like diabetes mellitus patient, renal failure patients, liver failure etc, but the role of other risk factors like smoking, obesity and the circulating concentration of fibrinogen along with genetic and environmental could not be definitely excluded. Despite these limitations, the presence of statistical significance of lipoprotein(a) associations with stroke severity in men of below 50 years age group opens a new scope for future research.

\section{References:}

[1]. Caplan LR. Caplan's stroke: A clinical approach.3rd Edn. Newyork: Butterworth Heieman;1996. p.5-12.

[2]. Warlow C. Stroke, transient ischemic attacks, and intracranial venous thrombosis. In: Donaghy M, Editor. Brain's diseases of the nervous system.11th Edn. Newyork: Oxford university press; 2001 p.789-793.

[3]. Poungavarin N. Strokes in developing countries. Lancet1998;352:(SIII)19-22. Bonita R. Epidemiology of Stroke. Lancet 1992;339:342 - 347.

[4]. Das SK, Banerjee TK, Biswas A et al. A prospective community based study of stroke in Kolkata, India. Stroke 2007;38:906-10.

[5]. Garraway WM, Wishnant JP, Drury I. The continuing decline in the incidence of stroke. Mayo clinProc 1983;58:520-3.

[6]. N adamuni S: Researchers identify stroke subtypes in India. Lancet 2002;359:500.

[7]. Kaul S, Sunitha P, SuvarnaA et al. Subtypes of ischemic strokes in Hyderabad, South India. Data from Hospital based stroke registry. Neurol India 2002;50:s1-s14.Sridharan R, Murthy BN. Prevalence and pattern of epilepsy in India. Epilepsia1999;40:631-63.

[8]. R adhakrishnan K, Pandian JD, Santoshkumar T, et al. Prevalence, knowledge, attitude, and practice of epilepsy in Kerala, South India. Epilepsia2000;41:1027-35.

[9]. Robinson RG. The clinical neuropsychiatry of stroke. Cognitive, behavioural and emotional disorders following vascular brain injury. Cambridge Cambridge university press; 1998.p.3-4.

[10]. Bhattacharya S, Prasarsaha S, Basu A, Das K. A 5 year prospective study of incidence, morbidity and mortality stroke profile on stroke in a rural community of Eastern India. J Indian Med Assoc 2005; Dalal P et al. Population-bases stroke survey in Mumbai, India: Incidence and 28-day case fatality. Neuroepidemiology 2008; 31: 254-61.

[11]. Sridharan S et al. Incidence, types, risk factors and outcome of stroke in a developing country: the Trivandrum Stroke Registry. Stroke 2009; 40: 1212-18.

[12]. Harsha Kumar H N, KalraBabusha, GoyalNayna. A study on stroke and its outcome in young adults (15- 45 Years) from coastal South India Year : 2011 | Volume: 36 | Issue No: 1 | Pg: 62- 65

[13]. Marc Fisher MD, Bo Norrving. 1st Global Conference on Healthy. Lifestyles and Non communicable diseases Control. Moscow, April 28-29, 2011.

[14]. Rooper AH, Brown RH. Editors. Cerebrovascular diseases. In: Adams and Victor's principles of Neurology. 8 thedn. New York: McGraw Hill; 2005.p.600-746.

[15]. Dalal PM. Stroke in young and elderly: Risk factor and strategies for stroke prevention. J Assoc Physicians India 1997;45:125-131

[16]. SHEP Cooperative research group. Prevention of stroke by antihypertensive drug treatment in older persons with isolated systolic hypertension. JAMA 1991;265: 3255 - 3264 .

[17]. Eastern Stroke and Coronary Heart Disease Collaborative Research Group. Bld Pressure, Cholesterol and Stroke in Asia. Lancet 1998;352:1801 07.

[18]. Warlow C. Stroke, transient ischemic attacks, and intracranial venous thrombosis. In: Donaghy M, Editor. Brain's diseases of the nervous system.11th Edn. Newyork: Oxford university press; 2001 p.789-793.

[19]. Sridharan R. Risk factors for Ischemic Stroke: A case control Analysis. Neuroepidemiology 1992;11:24 - 30.

[20]. Shahar E, Chambless LE, Rosamond WD, Boland LL, Ballantyne CM, McGovern PG,et al. Plasma lipid profile and incident ischemic stroke: the Atherosclerosis Risk in Com(ARIC) study. Stroke. 2003;34(3):623-631.

[21]. Albers JJ, Koschinsky ML, Marcovina SM (2007). "Evidence mounts for a role of the kidney in lipoprotein(a) catabolism". Kidney Int. 71 (10): 961-2. doi:10.1038/sj.ki.5002240.PMID 17495935.

[22]. Wolf PA, Thomas R, Dawber H, Thomas E. Epidemiologic assessment of chronic atrial fibrillation and risk of Stroke. The Framingham Study. Neurology 1978; 28:973 - 977 .

[23]. Brown RD, Whisnant JP, Sicks RD, O'Fallon WM, Wiebers DO. Stroke incidence, prevalence, and survival: secular trends in Rochester, Minnesota, through 1989. Stroke. 1996;27:373-380.

[24]. Wolf PA, D'Agostino RB, O'Neal MA, Sytkowski P, Kase CS, Belanger AJ, Kannel WB. Secular trends in stroke incidence and mortality: the Framingham Study. Stroke. 1992;23:1551-1555.

[25]. Iso H, Jacobs DR Jr, Wentworth D, Neaton JD, Cohen JD. Serum cholesterol levels and six-year mortality from stroke in 350,977 men screened for the multiple risk factor intervention trial. N Engl J Med. 1989;320:904-910.

[26]. Heiss G, Sharrett AR, Barnes R, Chambless LE, Szklo M, Alzola C. Carotid atherosclerosis measured by B-mode ultrasound in populations: associations with cardiovascular risk factors in the ARIC study. Am J Epidemiol. 1991;134:250-256.

[27]. Gordon T, Kannel WB, Castelli WP, Dawber TR. Lipoproteins, cardiovascular disease, and death: the Framingham Study. Arch Intern Med.1981;141(9):1128-1131.

[28]. Haheim LL, Holme I, Hjermann I, Leren P. Risk factors of stroke incidence and mortality: a 12-year follow-up of the Oslo Study. Stroke.1993;24(10):1484-1489. 